\title{
MODIFICATION OF NANOCRYSTALLINE MAGNETITE BY MILLING
}

\author{
K. Mažeika ${ }^{\mathrm{a}}$, J. Reklaitis ${ }^{\mathrm{a}}$, G. Lujanienè ${ }^{\mathrm{a}}$, D. Baltrūnas ${ }^{\mathrm{a}}$, and A. Baltušnikas ${ }^{\mathrm{b}}$ \\ ${ }^{a}$ Institute of Physics, Savanoriu 231, LT-02300 Vilnius, Lithuania \\ E-mail: kestas@ar.fi.lt \\ ${ }^{\mathrm{b}}$ Kaunas University of Technology, Donelaičio 73, LT-44029, Kaunas, Lithuania
}

Received 6 September 2006

\begin{abstract}
Structural changes in the nanocrystalline magnetite induced by mechanical milling were studied by means of Mössbauer spectroscopy and X-ray diffraction. Magnetite coated with the surfactant layer and that without surfactant both placed into ethanol were milled using the planetary ball mill. Mössbauer spectra of samples were recorded at 16-300 K temperature. According to the results of the study, milled nanocrystalline magnetite can be divided into unaffected initial ferrimagnetic magnetite, superparamagnetic magnetite, and "intermediate" magnetite. The stoichiometry of samples was also evaluated.
\end{abstract}

Keywords: Mössbauer spectroscopy, nanoparticles, magnetite, ball milling, structural changes

PACS: $76.80 .+\mathrm{y}, 75.50 . \mathrm{Tt}, 81.20 . \mathrm{Wk}$

\section{Introduction}

The ball milling of the bulk material is one of the cheapest methods for preparation and modification of nanocrystalline materials. The use of high energy ball mills for mechanical alloying is well known. The planetary mills were used for mechanical alloying of different elements, such as $\mathrm{Fe}$ with $\mathrm{Si}, \mathrm{Fe}$ and $\mathrm{Al}, \mathrm{Fe}$ and $\mathrm{Cr}$, and a lot of others [1-4]. Mechanical alloying of ternary or more complicated systems has been studied lately $[5,6]$. In the case of milling, one of the aims is to reduce the crystallite sizes and reach the nanometric size scale. For example, the bulk ferrite materials $\mathrm{Fe}_{3} \mathrm{O}_{4}$ [7, 8], $\mathrm{ZnFe}_{2} \mathrm{O}_{4}$ [9], and $\mathrm{CuFe}_{2} \mathrm{O}_{4}$ [10] were milled and the nanometric sizes were obtained. Milling is more effective when the bulk material is milled in a liquid such as acetone, methanol, or others. The crystalline size of magnetite was reduced to 6-7 nm after 100 hours of milling of bulk magnetite [7]. It is known that the properties of nanocrystalline materials depend on the method of their preparation. The changes in magnetoresistance of milled magnetite were observed in [11]. Milling induces a lot of defects. One of shortcomings in applying mills is that impurities from milling tools due to their abrasion can be introduced. It was also observed that depending on the milling conditions the oxidation of magnetite and the changes in its stoichiometry are possible [7].
The chemical precipitation methods can hardly be used to obtain effectively large quantities of nanoparticle material, but these can be easily obtained by mechanical milling. The method of chemical precipitation is used in this work for the preparation of initially nanosize magnetite which is milled afterwards to study the effect on the size and properties of nanocrystalline magnetite. The aims of the work were to determine the effectiveness of size reduction of nanoparticles with and without surfactant by milling and to investigate structural changes induced by milling. Mössbauer spectroscopy, X-ray diffraction, and scanning electron microscopy (SEM) were used in the study.

\section{Experimental}

Nanocrystalline magnetite was synthesized by the chemical precipitation method. Water solutions of $\mathrm{FeCl}_{3}$ and $\mathrm{FeCl}_{2}$ salts were mixed, heated, and $\mathrm{NH}_{4} \mathrm{OH}$ was added:

$$
\begin{aligned}
& \mathrm{FeCl}_{2}+ 2 \mathrm{FeCl}_{3}+8 \mathrm{NH}_{4} \mathrm{OH} \longrightarrow \\
& \mathrm{Fe}_{3} \mathrm{O}_{4} \downarrow+8 \mathrm{NH}_{4} \mathrm{Cl}+4 \mathrm{H}_{2} \mathrm{O} .
\end{aligned}
$$

The obtained nanocrystalline magnetite was placed into ethanol. Two different magnetite ferrofluids were prepared. In one of them the magnetite particles were 
coated with surfactant - oleic acid, whereas the other was without surfactant.

Magnetite in ethanol was milled using the planetary mill Pulverisette 6 at $300 \mathrm{rpm}$. The amount of $30 \mathrm{ml}$ of ferrofluid was placed into the $250 \mathrm{ml}$ hardened steel bowl with 6 stainless steel balls of $30 \mathrm{~mm}$ in diameter. The concentration of the first milled ferrofluid (without surfactant) was $20 \mathrm{mg} / \mathrm{ml}$ of $\mathrm{Fe}_{3} \mathrm{O}_{4}$. The concentration of the second ferrofluid (with surfactant) was $7 \mathrm{mg} / \mathrm{ml}$ of $\mathrm{Fe}_{3} \mathrm{O}_{4}$. The required amount of ferrofluid $(\approx 20 \mathrm{mg}$ of magnetite) was taken from the milling bowl and dried on a thin aluminium foil to prepare the samples for Mössbauer studies.

The changes in the composition of milled samples were characterized using Mössbauer spectroscopy. The constant acceleration Mössbauer spectrometer was applied in the transmission geometry. The ${ }^{57} \mathrm{Co}(\mathrm{Rh})$ source was used. Mössbauer spectra were measured at $16 \mathrm{~K}$ to room temperature. The low temperature measurements were accomplished using the closed cycle helium cryostat for Mössbauer spectroscopy.

The measured Mössbauer spectra are complicated and therefore, to determine changes in the spectra which occur during milling, different description methods were used. The spectra were described by evaluating the relative amounts of magnetically split (ferrimagnetic) magnetite, superparamagnetic magnetite, and "intermediate" group of phases, which takes into account the contributions of magnetite particles with the hyperfine field lower than $37 \mathrm{~T}$ and of steel impurities abraded from milling tools. The superparamagnetic phase is described by a single doublet. For the description of magnetically ordered phases many sextets are required.

In the description of magnetically split part of Mössbauer spectra, it was taken into account that the spectrum of bulk magnetite can be described by two sextets with a different hyperfine field $B$ and the isomer shift $\delta$. These subspectra are related to the tetrahedral (A) and octahedral (B) sublattices of magnetite and the ratio of their areas can be used to evaluate the stoichiometry of magnetite $[12,13]$. The spectrum of nanocrystalline magnetite is more complicated. The superparamagnetic relaxation of the magnetic moment of nanoparticles causes a decrease in the hyperfine field $B$. The influence of relaxation depends on the particle size, which has the lognormal distribution law for initial, unmilled magnetite. Therefore, the Mössbauer spectra of nanocrystalline magnetite should be described by sets of sextets, the hyperfine field of which is size- dependent. In the Mössbauer spectra description, the hyperfine field $B$ is defined by [14]

$$
B=B_{0}\left(1-\frac{1}{2} \alpha^{-1}-\frac{1}{2} \alpha^{-2}-\frac{5}{4} \alpha^{-3}\right) \text {. }
$$

The parameter $\alpha=\Delta E / k_{\mathrm{B}} T$, where $\Delta E$ is the barrier height for the relaxation of the magnetic moment, $T$ is temperature, $k_{\mathrm{B}}$ is the Boltzmann constant, and $B_{0}$ is the full hyperfine field which is observed when there is no relaxation (for bulk material). Though only two first members of series are usually used in Eq. (1) [14], the additional two members have allowed us to obtain slightly better consistency of the spectra description. In the case of non-interacting particles the parameter $\alpha=K V / k_{\mathrm{B}} T$, because the energy barrier for the relaxation of the magnetic moment is due to the magnetic anisotropy ( $K$ is the anisotropy constant and $V$ is the particle volume). For closely arranged nanoparticles, the strength of the magnetic dipole interaction between nanopartices can be sufficiently important. The dipole interaction modifies the energy barrier. In this case the evaluation of the energy barrier height is complicated because it depends on the order of magnetic moments and their dynamics. Depending on the interaction strength the dipolar interaction can either increase or decrease the energy barrier [15]. The interaction of magnetic moments of the particles can be described as the interaction of the magnetic moment $m=M_{s} V$ with the magnetic field from surrounding particles and therefore can also be proportional to the volume of the particle. $M_{s}$ is the bulk magnetization. Taking this into account, the parameter $\alpha$ which is used in the description of spectra is distributed by the lognormal law as is the particle volume $V$ [16].

For description of the contribution of ferrimagnetic magnetite in Mössbauer spectra the sets of sextets are used as a function of $\alpha$. The relative area of sextet in the set is proportional to the probability $P$ of the distribution of $\alpha$

$$
P(\alpha)=\frac{1}{\alpha \sigma \sqrt{2 \pi}} \exp \left(-\frac{\ln ^{2} \frac{\alpha}{\alpha_{0}}}{2 \sigma^{2}}\right) .
$$

The hyperfine field $B$ of sextet in the set is defined by Eq. (1).

The part of magnetically split magnetite in Mössbauer spectra is fitted using the parameters: the average $\alpha_{0}$ and its deviation $\sigma$. Then the subspectra parameters - the static hyperfine field $B_{0}$ and the isomer shift - are fixed and equal to those of bulk magnetite. The hyperfine fields $B_{0}$ at room temperature are $49.8 \mathrm{~T}$ 
for tetrahedral (A) and $46 \mathrm{~T}$ for the octahedral (B) sublattices of magnetite [13].

The contribution of steel impurities, introduced from the milling tools and magnetite particles which are reduced in size but still are ferrimagnetic, is described by the distribution of the hyperfine field $P(B)$. The hyperfine field $B$ of the steel particles which are abraded from the grinding bowl and the balls also decreases due to relaxation of the magnetic moment when particle sizes are small. Moreover, the hyperfine field $B$ is affected by the atoms of $\mathrm{Cr}$ and $\mathrm{Ni}$ which are the constituents of steel of which milling tools are made. The $\mathrm{Cr}$ atom in the first coordination shell of the iron atom causes a decrease in the hyperfine field $B$ by $2.1 \mathrm{~T}$, while such $\mathrm{Ni}$ atom causes an increase in $B$ by $0.34 \mathrm{~T}$ [17]. Thus, a wide region (17-37 T) of the hyperfine field $B$ is needed for the description of Mössbauer spectra. The sextets with the hyperfine field in this region account for the area of spectra of magnetite reduced in size and that of steel impurities, though the isomer shifts of magnetite differ from that of iron in steel. The isomer shift $\delta$ for the sextets of the distribution $P(B)$ is fitted as a linear dependence on the hyperfine field $B: \delta=\delta_{0}+$ const $\cdot B$. To separate the contribution of steel impurities from that of milled magnetite particles, the low temperature Mössbauer measurements are carried out. At low temperature the thermal relaxation of the magnetic moment stops and hyperfine fields of subspectra increase approaching their static values which are different for magnetite and steel.

The X-ray diffraction studies were used to check the composition of the samples of nanocrystalline magnetite as well as to evaluate the crystalline sizes of magnetite from the X-ray line width. For that purpose the Scherrer equation was used [18]. The influence of microstrain on the line width was evaluated to be negligible.

The scanning electron microscopy (SEM) study at different resolution revealed the structure of ferrofluid of magnetite in ethanol showing the agglomeration of particles.

\section{Results and discussions}

Selected spectra of the studied samples measured at room temperature are shown in Fig. 1. The Mössbauer spectrum of initially synthesized magnetite has mainly a magnetically split part which is described by sextets. The magnetite lines are broadened, which is the effect of relaxation of the magnetic moment due to relatively small particle sizes. At lower temperature the line width decreases as the relaxation rate decreases (Fig. 2).

Two samples were examined by X-ray studies (Fig. 3). The X-ray pattern of the milled sample showed the presence of iron which gets into the samples from milling tools. X-ray studies also allowed evaluating the average particle sizes which were slightly different for both ferrofluids. The determined average size of magnetite particles of the first ferrofluid (without surfactant) milled for $6 \mathrm{~h}$ was $17.4 \pm 0.5 \mathrm{~nm}$, while the initial size of magnetite particles of the second ferrofluid (with surfactant) was $16.2 \pm 0.2 \mathrm{~nm}$.

During milling, a relative amount of the paramagnetic part of Mössbauer spectra increases. The isomer shift (with respect to $\alpha$-Fe) of doublet which describes the paramagnetic part is $\delta=0.36 \pm 0.03 \mathrm{~mm} / \mathrm{s}$ and its quadruopole splitting is $\Delta=0.92 \pm 0.03 \mathrm{~mm} / \mathrm{s}$. The changes in the amounts of magnetically split unaffected magnetite, superparamagnetic magnetite phase, and "intermediate" phases that include the impurities abraded from milling tools and ferrimagnetic magnetite reduced in size are shown in Fig. 4. Changes in amounts of the magnetite ferrimagnetic unaffected and superparamagnetic parts, from which it is evident that milling process for ferrofluid without surfactant is more rapid, are shown separately.

The low temperature Mössbauer studies (Figs. 2 and 5) revealed the origin of the spectra area described by sextets having intermediate hyperfine fields within 17-37 T. As the relaxation of the magnetic moment of particles stops due to an increase in the relative barrier height at low temperatures, the part of area of Mössbauer spectra moves from the area of "intermediate" hyperfine fields to the area of hyperfine fields which are similar to those of unaffected magnetite. Only the area which is left at the lowest temperature and is close to the iron specific hyperfine field is due to steel which is abraded from milling tools (Fig. 5). The paramagnetic part of magnetite for the same reasons becomes magnetically split. It can be seen that at temperature of $16 \mathrm{~K}$ a relative amount of the magnetic part of magnetite with hyperfine fields close to those of bulk magnetite increases more than twice compared with that at room temperature. For the sample of the second ferrofluid (with surfactant) milled for $6 \mathrm{~h}$ it increases from 30 to $64 \%$. Accordingly, the amount of "intermediate" group of phases decreases from 56 to $33 \%$.

The relative amounts of phases having "intermediate" hyperfine fields are larger for dried samples of the second ferrofluid. The steel impurities according to the low temperature measurements may be responsible for 

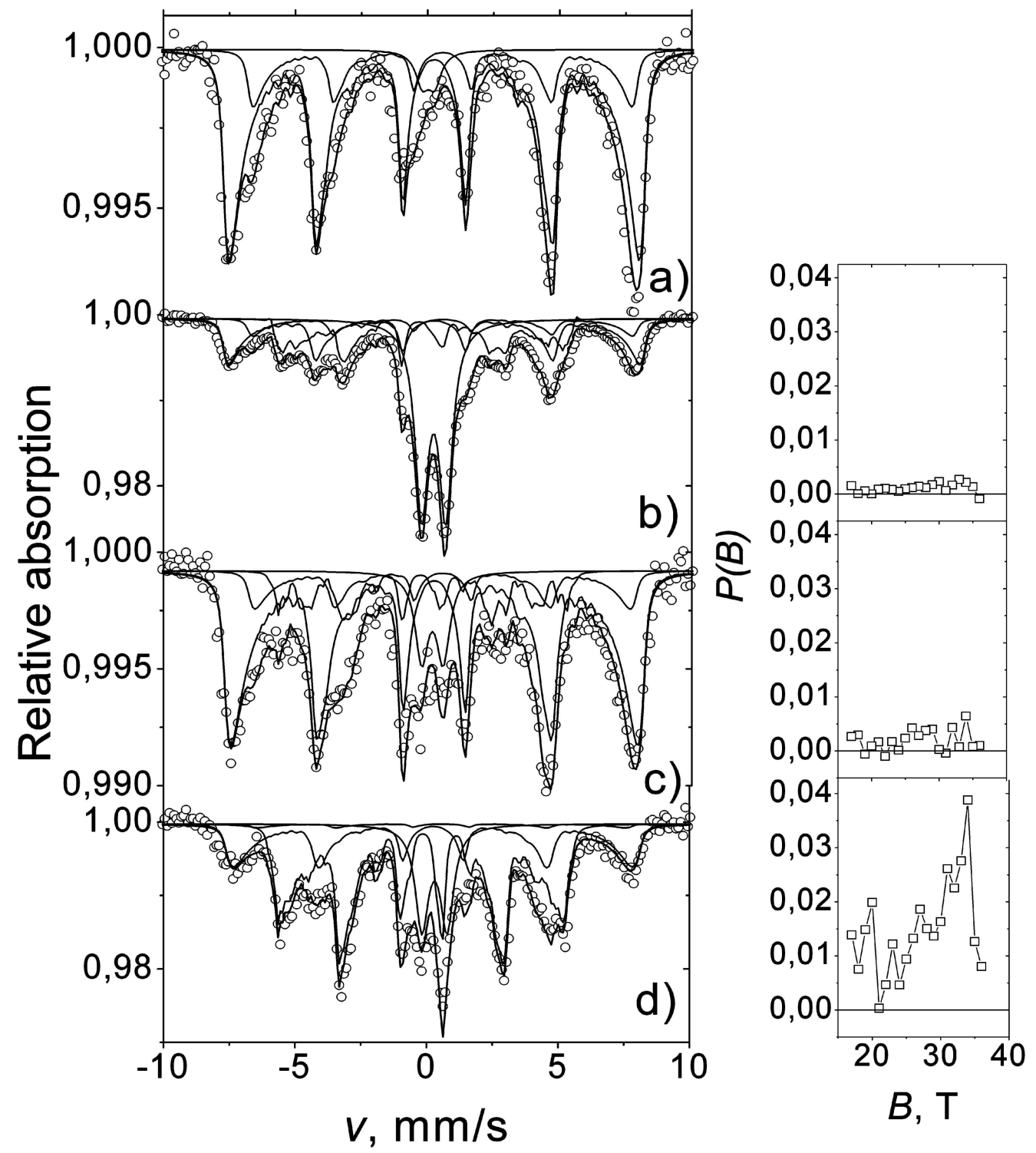

Fig. 1. Mössbauer spectra (left) and their description for nanocrystalline magnetite samples measured at room temperature: (a) initial magnetite without surfactant, (b) magnetite milled for $6 \mathrm{~h}$ without surfactant, (c) magnetite milled for $2 \mathrm{~h}$ with surfactant, (d) magnetite milled for $10 \mathrm{~h}$ with surfactant. Hyperfine field distribution $P(B)$ for "intermediate" hyperfine field phases is given on the right.

approximately half of this "intermediate" phase area. Despite an approximately two times larger amount of "intermediate" phases in the second ferrofluid as compared with the first one, it can be explained taking into account different concentration of magnetite in ferrofluids. If the concentrations of impurities in ferrofluids are approximately the same, their relative concentration as compared with those of magnetite will be more than twice higher in the second ferrofluid. The description of Mössbauer spectra gives the hyperfine distributions shown on the right side of Fig. 1. The $P(B)$ distribution with much lower hyperfine fields than that of iron (33.1 T) may arise only due to relaxation of small particles. If the particles of steel are relatively large (according to X-ray data their size is similar to that of non-milled magnetite particles), this area is mainly due to magnetite particles reduced in size which are still large to cause magnetic splitting of spectra.

The description of the magnetically split part of spectra of magnetite samples by two complex subspectra composed of the sets of sextets allowed us to evaluate the relative height of the barrier $\alpha$. The parameter $\alpha$ does not considerably change during milling and its average values are 6.7 for the first ferrofluid and 5.9 for the second. These values agree well with the $\mathrm{X}$-ray data on the crystalline size of studied samples. If only the magnetic anisotropy energy is taken into account, the relative barrier height is $\alpha=K V / k_{\mathrm{B}} T$. For magnetite with the anisotropy constant $K=1.07 \cdot 10^{4} \mathrm{~J} \cdot \mathrm{m}^{-3}$ [19], 


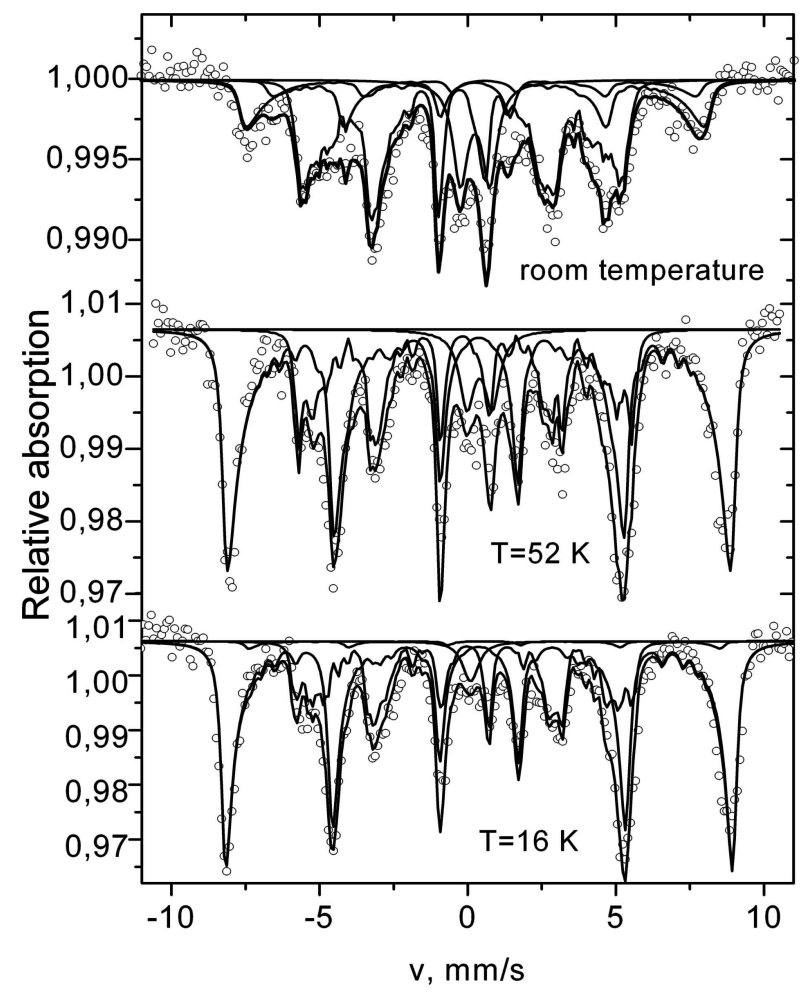

Fig. 2. Mössbauer spectra of the nanocrystalline magnetite milled for $6 \mathrm{~h}$ with surfactant measured at different temperatures.

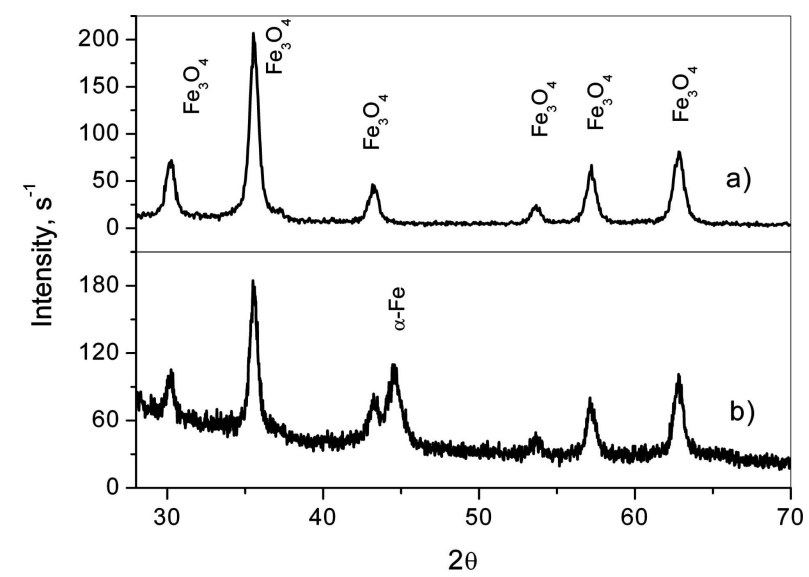

Fig. 3. X-ray diffraction spectra of nanocrystalline magnetite samples: (a) initial magnetite with surfactant, (b) magnetite ferrofluid milled for $6 \mathrm{~h}$ without surfactant.

the calculated $\alpha$ values are 7.1 and 5.7 for the first and second ferrofluid, respectively.

The ratio of areas of two magnetite subspectra depends on the stoichiometry of magnetite. The subspectrum with the static hyperfine field $B_{0}=49.8 \mathrm{~T}$ is due to $\mathrm{Fe}^{3+}$ ions in the tetrahedral (A) sublattice and unpaired $\mathrm{Fe}^{3+}$ ions in the octahedral (B) sublattice of magnetite. The subspectrum with the lower static hyperfine field $B_{0}=46 \mathrm{~T}$ is due to paired $\mathrm{Fe}^{3+}$ and $\mathrm{Fe}^{2+}$ ions in the octahedral sublattice (B) $[12,13]$. The experimental ratio of these subspectra $S_{\mathrm{Fe}^{2+}+\mathrm{Fe}^{3+}} / S_{\mathrm{Fe}^{3+}}$

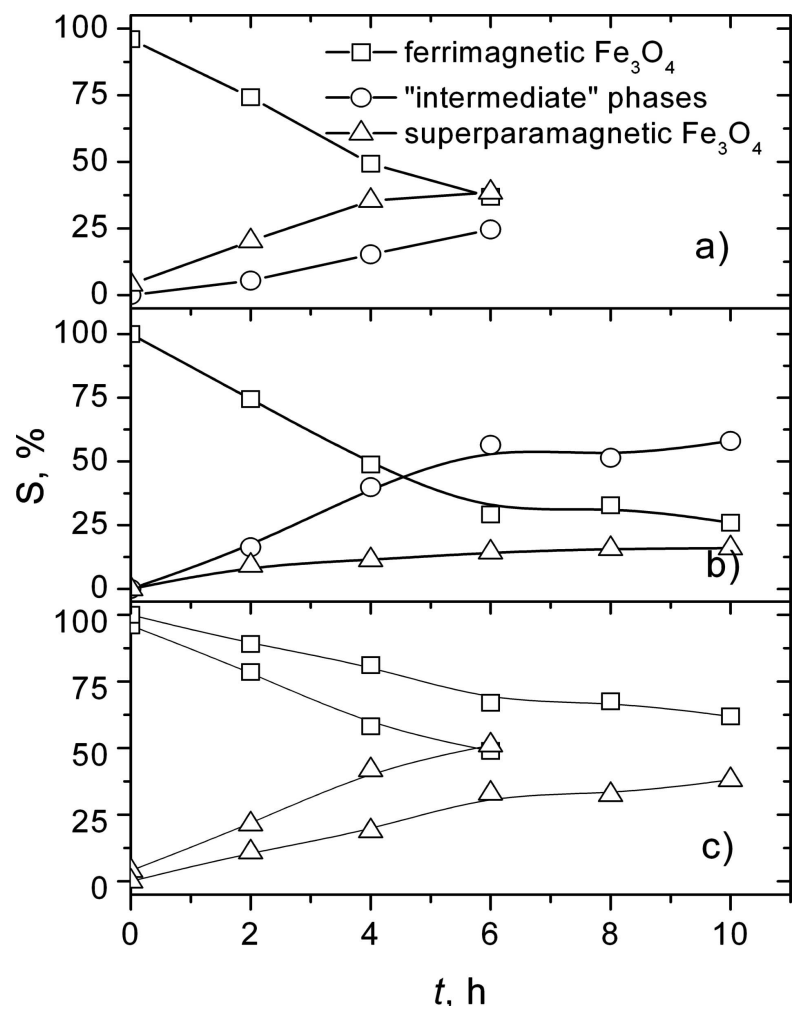

Fig. 4. Dependence of relative amounts of ferrimagnetic $\mathrm{Fe}_{3} \mathrm{O}_{4}$, superparamagnetic $\mathrm{Fe}_{3} \mathrm{O}_{4}$, and "intermediate" hyperfine field phases on milling time $t$ for: (a) magnetite ferrofluid without surfactant, (b) magnetite ferrofluid with surfactant. The relative amounts of ferrimagnetic and superparamagnetic $\mathrm{Fe}_{3} \mathrm{O}_{4}$ for both ferrofluids are shown in (c).

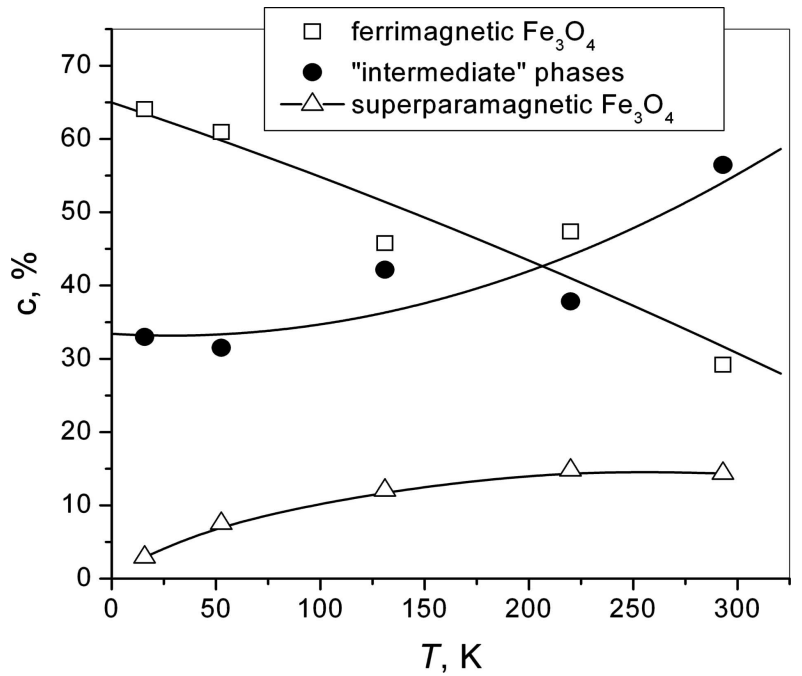

Fig. 5. Dependence of relative amounts of ferrimagnetic $\mathrm{Fe}_{3} \mathrm{O}_{4}$, superparamagnetic $\mathrm{Fe}_{3} \mathrm{O}_{4}$, and "intermediate" hyperfine field phases on temperature for magnetite ferrofluid with surfactant milled for $6 \mathrm{~h}$. 


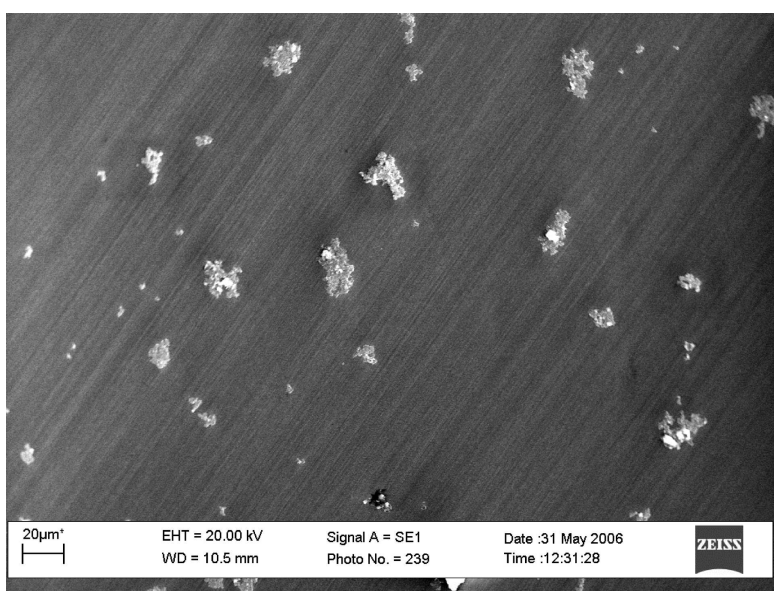

(a)

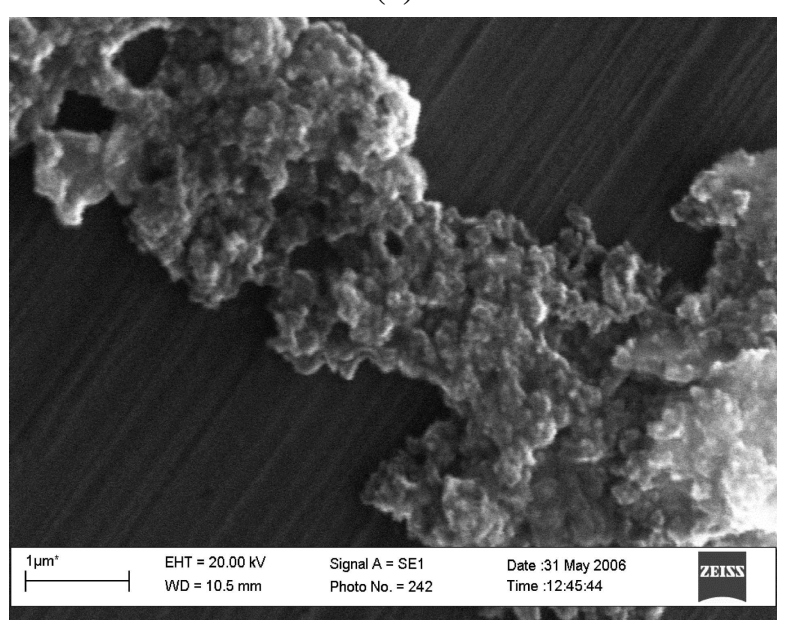

(b)

Fig. 6. SEM pictures of the magnetite ferrofluid (without surfactant).

for the studied ferrofluids is approximately 0.3. For stoichiometric magnetite all ions in the octahedral sublattice (B) are paired and, therefore, the ratio will be equal to 2. According to the given ratio of areas the initial formula of studied nonstoichiometric magnetite is $\left(\mathrm{Fe}^{3+}\right)_{\mathrm{A}}\left(\mathrm{Fe}_{0.32}^{2+} \mathrm{Fe}_{1.45}^{3+}\right)_{\mathrm{B}} \mathrm{O}_{4}$. In addition, the experimental data have shown that the oxidation of magnetite is not observed in the magnetically split part (there are no changes in stoichiometry of magnetite during milling). The difference of stoichoimetry is not evaluated for crushed particles. Therefore, for this purpose additional studies should be done.

As one can see in the SEM pictures (Fig. 6), magnetite particles agglomerate in large 2-20 $\mu \mathrm{m}$ globules of irregular form. The accumulation of particles can be determined by the magnetic attraction of particles due to relatively large particle sizes [20] that is equally important to the uncoated particles and those coated with the surfactant layer. Due to the accumulation of particles the segregation in both ferrofluids occurs. There- fore, during milling, the particles in these globules rub against each other. According to the results of the study this process is apparently more important than the direct mechanical effect of milling tools. The lower rate of an increase in the paramagnetic part of the second ferrofluid indicates that the surfactant layer which covers particles suppresses the milling process.

According to the results of the study, different fractions in magnetite starting with initial unaffected magnetite particles can be seen. Some part of particles are crushed into very small ones which are superparamagnetic (usually with the $<10 \mathrm{~nm}$ size), among which there are larger particles which are still ferrimagnetic, but the hyperfine field is considerably lower than that of the initial nanocrystalline magnetite of $16-18 \mathrm{~nm}$ size.

\section{Conclusions}

The structural changes induced in nanocrystalline magnetite dispersed in ethanol were observed. The amounts of unaffected by milling ferrimagnetic, superparamagnetic, and "intermediate" magnetite were determined from Mössbauer spectra, for the description of which different methods were used. The description of the magnetically split part of spectra allowed us to state that stoichiometry of this part of magnetite did not change during milling.

The initially synthesized nanocrystalline magnetite, with the sizes of particles from 16 to $18 \mathrm{~nm}$, determines a magnetically split part of magnetite in Mössbauer spectra. During milling for $6-10 \mathrm{~h}$ the amount of superparamagnetic magnetite caused due to the $<10 \mathrm{~nm}$ size particles as well as the amount of the intermediate size particles increased and became larger than the amount of unaffected nanocrystalline magnetite. The efficiency of milling was larger for the magnetite ferrofluid with particles not coated with the surfactant layer as compared with that for ferrofluid with coated particles. The steel impurities abraded from milling tools were also observed.

\section{Acknowledgements}

We wish to thank Dr A. Selskis and Dr R. Juškenas from the Institute of Chemistry (Lithuania) for SEM and XRD studies. 


\section{References}

[1] L. Yuzhi, Z. Chenhui, Z. Sanyuan, and Z. Guien, Mössbauer study of products of low energy milled $\mathrm{Fe}_{30} \mathrm{Si}_{70}$, J. Phys: Condens. Matter 13, 6019-6029 (2001).

[2] G.F. Goya and H.R. Rechenberg, Mechanosynthesis of intermetallic $\mathrm{Fe}_{100-x} \mathrm{Al}_{x}$ obtained by reduction of $\mathrm{Al} / \mathrm{Fe}_{2} \mathrm{O}_{3}$ composite, J. Phys: Condens. Matter 12, 10579-10590 (2000).

[3] B.F.O. Costa, S.M. Dubiel, and J. Cielak, Investigation of a $\mathrm{Cr}_{42.2} \mathrm{Fe}_{57.8}$ alloy prepared by mechanical alloying, J. Phys: Condens. Matter 18, 3263-3276 (2006).

[4] A. Cialka, Mechanical alloying - a method for processing and creating of new materials, Nukleonika 39, 4146 (1994).

[5] J.A. De Toro, M.A. Lopez de la Torre, M.A. Arranz, J.M. Riveiro, J.L. Martinez, P. Palade, and G. Filoti, Nonequilibrium magnetic dynamics in mechanically alloyed materials, Phys. Rev. B 64, 0944381-9 (2001).

[6] V. Neu and L. Schultz, Two-phase high-performance $\mathrm{Nd}-\mathrm{Fe}-\mathrm{B}$ powder by mechanical milling, J. Appl. Phys. 90, 1540-1544 (2001).

[7] G.F. Goya, Handling the particle size and distribution of $\mathrm{Fe}_{3} \mathrm{O}_{4}$ nanoparticles through ball milling, Solid State Commun. 130, 783-787 (2004).

[8] E. Bonetti, L. Del Bianco, S. Signoretti, and P. Tiberto, Synthesis by ball milling and characterization of nanocrystalline $\mathrm{Fe}_{3} \mathrm{O}_{4}$ and $\mathrm{Fe} / \mathrm{Fe}_{3} \mathrm{O}_{4}$ composite system, J. Appl. Phys. 89, 1806-1815 (2001).

[9] C.N. Chinnasamy, A. Narayanasamy, N. Ponpandian, K. Chattopadhyay, H. Guerault, and J.M. Greneche, Magnetic properties of nanostructured ferrimagnetic zinc ferrite, J. Phys: Condens. Matter 12, 7795-7805 (2000).
[10] G.F. Goya, H.R. Rechenberg, and J.Z. Jiang, Structural and magnetic properties of ball milled copper ferrite, J. Appl. Phys. 84, 1101-1108 (1998).

[11] X.Y. Zhang, Y.J. Chen, L.N. Fan, and Z.Y. Li, Enhancement of low-field magnetoresistance in $\mathrm{Fe}_{3} \mathrm{O}_{4}$ particles induced by ball milling, Solid State Commun. 137, 673-677 (2006).

[12] K. Volenik, M. Seberini, and J. Neid, A Mössbauer and $\mathrm{X}$-ray diffraction study of nonstoichiometry in magnetite, Czech. J. Phys. B 25, 1063-1071 (1975).

[13] J.M. Daniels and A. Rosencwaig, Mössbauer spectroscopy of stoichiometric and non-stoichiometric magnetite, J. Phys. Chem. Solids 30, 1561-1571 (1969).

[14] M.F. Thomas and C.E. Johnson, in: Mössbauer Spectroscopy, eds. D.P.E. Dickson and F.J. Berry (Cambridge University Press, Cambridge, 1986), p. 193.

[15] S. Morup and E. Tronc, Superparamagnetic relaxation of weakly interacting particles, Phys. Rev. Lett. 72, 3278-3281 (1994).

[16] O. Michele, J. Hesse, H. Bremers, E.K. Polychroniadis, K.G. Efthimiadis, and H. Ahlers, Magnetization experiments on frozen ferrofluids, J. Phys: Condens. Matter 16, 427-443 (2004).

[17] F. van der Woude and K.W. Maring, in: Proceedings of International Conference on Mössbauer Spectroscopy, Vol. 2, eds. D. Barb and D. Tarina (Bucharest, 1977), pp. 133-161.

[18] C.S. Barrett and T. B. Massalski, Structure of Metals (Metallurgiya, Moscow, 1984), p. 179 [in Russian].

[19] Tables of Physical Units, Handbook, ed. I.K. Kikoin (Atomizdat, Moscow, 1976), p. 566 [in Russian].

[20] K. Butter, P.H.H. Bomans, P.M. Frederik, G.J. Vroege, and A.P. Philipse, Direct observation of dipolar chains in iron ferrofluids by cryogenic electron microscopy, Nature Materials 2, 88-91 (2003).

\title{
NANOKRISTALINIO MAGNETITO MODIFIKAVIMAS MALANT
}

\author{
K. Mažeika ${ }^{\mathrm{a}}$, J. Reklaitis ${ }^{\mathrm{a}}$, G. Lujaniene ${ }^{\mathrm{a}}$, A. Amulevičius ${ }^{\mathrm{a}}$, D. Baltrūnas ${ }^{\mathrm{a}}$, A. Baltušnikas ${ }^{\mathrm{b}}$ \\ ${ }^{a}$ Fizikos institutas, Vilnius, Lietuva \\ ${ }^{\mathrm{b}}$ Kauno technologijos universitetas, Kaunas, Lietuva
}

\section{Santrauka}

Nanokristalinis magnetitas etanolyje buvo malamas rutuliniu malūnu (Pulverisette 6). Magnetito sandaros pokyčiai buvo pastebimi Mesbauerio (Mössbauer) spektroskopijos ir Rentgeno (Röntgen) difrakcijos metodais. Viename iš malamų feroskysčių magnetito nanodalelès, kurių didumas pagal Rentgeno difrakcijos duomenis $\approx 16-17 \mathrm{~nm}$ ir kurios yra pagamintos cheminio nusodinimo metodu, prieš jas patalpinant etanolyje buvo padengtos paviršiaus ak- tyviaja medžiaga (oleino rūgštimi). Panaudojus Mesbauerio spektroskopiją, buvo îvertinami beveik nepaveikto ferimagnetinio (dalelių dydžiai $\approx 16-17 \mathrm{~nm}$ ), paramagnetinio (susmulkintos dalelès iki $10 \mathrm{~nm}$ dydžio) ir tarpinio magnetito santykiniai kiekiai ir jų kitimas malant. Paveiktos susmulkintos nanokristalinio magnetito dalies kiekis po 6-10 valandų malimo viršijo nepaveikto magnetito kiekį. Nustatyta, kad feroskysčiui su aktyviaja paviršiaus medžiaga nepadengtomis dalelemis malimo efektyvumas didesnis. Malant magnetitą etanolyje stechiometrijos kitimo (oksidacijos) nepastebèta. 